\title{
Sublethal Antimony (III) Exposure of Freshwater Swamp Shrimp (Macrobrachium Nipponense): Effects on Oxygen Consumption and Hepatopancreatic Histology
}

\author{
Jen-Lee YANG ${ }^{1,2 \star}$, Tung-Jer HU ${ }^{3}$, Hong-Yuan LEE $^{4}$ \\ ${ }^{1}$ Department of Life Science, Chinese Culture University, Taipei, Taiwan, China \\ ${ }^{2}$ Center of General Education, National Taipei College of Business, Taipei, Taiwan, China \\ ${ }^{3}$ Department of Computer Application Engineering, Lanyang Institute of Technology, Taiwan, China \\ ${ }^{4}$ Department of Civil Engineering, National Taiwan University, Taipei, Taiwan, China \\ E-mail:d88225003@yahoo.com.tw \\ Received October 28, 2009; revised November 12, 2009; accepted November 20, 2009
}

\begin{abstract}
This study was an attempt to realize the effects of antimony on freshwater swamp shrimp (Macrobrachium nipponense). An experiment of this nature, which have not previously been carried out in this species. First, median lethal concentrations were determined in acute toxicity tests. The 96-h LC50 value was 6.748 (5.728-7.950) $\mathrm{mg} \mathrm{Sb} / 1$ for adult $M$. nipponense and 1.635 (1.271-2.103) $\mathrm{mg} \mathrm{Sb/l} \mathrm{for} \mathrm{juvenile} \mathrm{M.} \mathrm{nipponense.}$ Juvenile $M$. nipponense were exposed to 4 different sublethal levels of antimony $(0.1,0.4,0.8$, and $1.2 \mathrm{mg}$ $\mathrm{Sb} / \mathrm{l}$ ) over a 7-d test period and a 7-d recovery period. After $30 \mathrm{~min}$ (acute), there was an increase in the amount of oxygen consumed in all exposed groups. On days 3, 7, and 14, decreases in oxygen consumption were significant $(\mathrm{p}<0.05)$ for the higher-exposure level groups $(0.8$ and $1.2 \mathrm{mg} / \mathrm{l})$. Light microscopy investigations showed histopathological alterations in the hepatopancreas which correlated with exposure concentrations. The alterations included degenerative changes in the lumen, a reduction in the lumen volume, and injury to epithelial cells in the histoarchitecture of hepatopancreas.
\end{abstract}

Keywords: Antimony, Macrobrachium Nipponense, Oxygen Consumption, Hepatopancreas

\section{Introduction}

Antimony ( $\mathrm{Sb})$ compounds such as indium antimony $(\mathrm{InSb})$ and gallium antimony $(\mathrm{GaSb})$ are important materials for the manufacture of integrated circuits and optoelectronic devices in the semiconductor industry [1]. Manufacturing processes devoted to the fabrication of GaSb-based semiconductor devices generate large volumes of wastes that contain the toxic metals antimony and gallium. In addition, both metals are listed as hazards by the Environmental Protection Agency in the US [2]. Previous reports indicated that mammalian exposure to trivalent forms of $\mathrm{Sb}$ can cause severe liver damage, hemolysis, hematuria, and circulatory disease. And antimony trichloride $(\mathrm{SbCl} 3)$ induced sister chromatid exchanges (SCEs) in V79 cells and apoptosis in human fibroblasts (HFs), a human bronchial epithelial cell line (BES-6), and a Chinese hamster ovary cell line (CHOK1) $[3,4]$.

Industrial spills can lead to high concentrations of toxic materials in water, affecting freshwater ecosystems with acute and chronic health effects. Toxicants may significantly damage certain physiological and biochemical processes when they enter the organs of fishes [5]. The liver is an important organ involved in metabolic processes and in detoxification of xenobiotics. In some situations, poisonous materials may accumulate in the liver to toxic levels and cause pathological alterations [6]. Histopathological alterations are recognized and commonly used diagnostic tools in aquatic toxicology studies [7]. Oxygen consumption is widely considered to be a critical factor for evaluating the physiological response and a useful variable for an early warning for monitoring aquatic organisms [8]. Like most aquatic organisms, they maintain their oxygen consumption at a constant level along a gradient of environmental oxygen concentrations, until a critical oxygen concentration is reached, and below which oxygen consumption begins to fall. Under conditions of stress, this critical oxygen concentration is likely to increase, reflecting organisms' 
capacity for coping with environmental perturbations [9, 10].

Swamps are among the world's most productive wetland ecosystems, and they are also important as nursery grounds for many ecologically and economically important species. The freshwater swamp shrimp (Macrobrachium nipponense) is a common aquatic invertebrate widely distributed in upper and middle sections of rivers throughout the eastern Asia-Pacific area. The purposes of this study were to examine the effects of antimony on acute toxicity and the effects of sublethal antimony concentrations on the oxygen consumption and hepatopancreastic histology of $M$. nipponense, so that this evidence could then be used to evaluate possible adverse effects of this metal on the freshwater swamp shrimp.

\section{Materials and Methods}

Juvenile and adult of the freshwater swamp shrimp ( $M$. nipponense) were obtained from local commercial suppliers. Shrimp were transported to a glass aquarium in our laboratory which was equipped with a water-cycling device; dechlorinated tap water (with a $\mathrm{pH}$ of 7.4-8.1, dissolved oxygen (DO) of 7.0-7.7 mg/l, and hardness of $38-45 \mathrm{mg} \mathrm{CaCO} / \mathrm{l})$ was used during the entire experiment. The temperature was maintained at $24.0 \pm 0.5^{\circ} \mathrm{C}$, and a 12-h light and 12-h dark photoperiod was used. Shrimp were acclimated for 2 weeks and fed an aquarium shrimp mixture every day. Juvenile (4 weeks old, $0.42 \pm 0.17 \mathrm{~cm}$ in total length) were used for acute toxicity tests and oxygen consumption tests; adult (17 weeks old, $1.2 \pm 0.38 \mathrm{~cm}$ in total length) were used for the acute toxicity tests and histological examinations in the initial experiments. Antimony trichloride (purity $\geqq 99 \%$ ) was purchased from Sigma (St. Louis, MO, USA). Stock solutions were prepared in deionized water $(1000 \mathrm{mg} / \mathrm{l}$ test chemical in $0.1 \%$ nitric acid).

Laboratory static renewal tests [11] were conducted to determine the median lethal concentrations (LC50) for juvenile and adult $M$. nipponense. Ten shrimp of similar size were randomly sampled and placed in 10- 1 glass beakers. After $24 \mathrm{~h}$ of acclimat izat ion, the shrimp were exposed to different ant imony concent rat ions $(0,0.1$, $0.2,0.5,1.0,2.0,4.0,8.0,12.0,14.0$, and $16.0 \mathrm{mg} \mathrm{Sb} / \mathrm{l})$ for $96 \mathrm{~h}$ or more. The cont rol and each t reatment with 4- 1 testing solution, and all groups were run in duplicate. Dur ing the exper iment, dead shrimp were removed, and the mortality was recorded. The LC50 of antimony and its $95 \%$ confidence limits for $M$. nipponense were calculated using a Basic program from the probit analysis described by [12].

The oxygen consumption analysis was carried out using a former method with slight modification [8]. Groups of 20 juvenile $M$. nipponense were randomly sampled and placed in 10-1 glass beakers with 4-1 test ing solut ion; triplicate shrimp were then respectively exposed to a test solution of $0.0,0.1,0.4,0.8$, and $1.2 \mathrm{mg} \mathrm{Sb} / 1$. Sublethal levels of antimony were equivalent to approximately $6 \%$, $24 \%, 49 \%$, and $73 \%$ of the $96-\mathrm{h}$ LC50 value $(1.635 \mathrm{mg}$ $\mathrm{Sb} / \mathrm{l})$ according to acute toxicity tests. Twice a week, $50 \%$ of the water was renewed with standard water containing antimony to maintain constant environmental conditions throughout the entire experimental period. The exposure time was 1 week, followed by a 1-week recovery period in $\mathrm{Sb}$-free water.

Both control and exposed samples were taken after 30 $\min$ (for acute exposure), and $3^{\text {th }} \mathrm{d}, 7^{\text {th }} \mathrm{d}$, and $14^{\text {th }} \mathrm{d}$ for estimation of oxygen consumption. Oxygen consumption tests were customarily carried out by sealing two juvenile $M$. nipponense in a $325-\mathrm{ml}$ respiratory jar capacity with an oxygen electrode (Microprocessor Oximeter, WTW, Heidelberg, Germany). All respiratory jars contained up to $7 \mathrm{mg} / \mathrm{l}$ DO before the initial measurement. At each interval, two juvenile $M$. nipponense were put into a respiratory jar with an acclimatization time of 30 min as recorded earlier, and then the oxygen consumption was estimated. We allowed them to deplete the oxygen until death occurred, and the residual dissolved oxygen was measured using a multiple-range temperature and oxygen analyzer and recorder (Yokogawa, Tokyo, Japan). Oxygen consumption (QO2, mg O2/kg/h) was calculated as follows:

$$
\mathrm{QO}_{2}=\Delta \mathrm{ppm} \times 1 / \mathrm{BW} \times \mathrm{V} \times 1 / \mathrm{t}
$$

where $\mathrm{QO}_{2}$ is the amount of oxygen $(\Delta \mathrm{ppm})$ consumed in the interval $\mathrm{t}(\mathrm{h})$ and $\mathrm{BW}$ is the wet body weight $(\mathrm{kg})$ at the start and at the end of the test period.

Adult $M$. nipponense for sublethal tests were randomly placed in 20-1 glass aquaria with 10-1 test ing solut ion. Every aquarium contained 10 shrimp which were exposed to the following concentrations: $0.2,1.0$, and 4.0 $\mathrm{mg} \mathrm{Sb} / 1$ test solutions and a control. Sublethal levels of antimony were equivalent to approximately $3 \%, 15 \%$, and $60 \%$ of the $96-\mathrm{h} \mathrm{LC50}$ value $(6.748 \mathrm{mg} \mathrm{Sb} / \mathrm{l}) \mathrm{ac}-$ cording to the acute toxicity tests. Twice a week, $50 \%$ of the water was renewed with standard water containing antimony to maintain constant environmental conditions throughout the entire experimental period.

Four adult $M$. nipponense per exposure concentration were anesthetized with MS-222 (1:6000) (Sigma, St. Louis, MO, USA) and sacrificed after 2 weeks of exposure. Shrimp hepatopancreases were collected, fixed in $4 \%$ buffered formalin, and routinely processed for examination using standard techniques with hematoxylin and eosin (H\&E).

All values of oxygen consumption assessment were performed with one-way analysis of variance (ANOVA). Duncan's multiple-range test was used to evaluate the mean difference among individual groups at the 0.05 significance level. 


\section{Results and Discussion}

According to the static renewal method for acute toxicity testing, median lethal concentrations (LC50) of antimony for swamp shrimp ( $M$. nipponense) were calculated. The calculated 48- and 96-h LC50 values are listed in Table 1. From our investigation, juvenile $M$. nipponense were found to be more susceptible than adults $M$. nipponense to acute antimony toxicity. 96-h LC50 of antimony to juvenile zebrafish (Brachydanio rerio) was $4.65 \mathrm{mg} \mathrm{Sb} / \mathrm{l}$, and to juvenile common carp (Cyprinus carpio), larval tilapia (Oreochromis mossambicus), juvenile red seabream (Pargus major), and juvenile sheepshead minnows (Cyrinodan variegatus), were $14.05,18.9,12.4$, and $6.2-8.3 \mathrm{mg} \mathrm{Sb} / 1$, respectively [2,13-16]. No toxic effect was seen at $0.2 \mathrm{mg}$ $\mathrm{Sb} / 1$ in the acute toxicity testing of juvenile $M$. nipponense, which is equivalent to $12 \%$ of the $96-\mathrm{h} \mathrm{LC50}$ value, and is in close agreement with the concept of a safe level (one-tenth of the 96-h LC50 value) as described by [17]. Less than $0.2 \mathrm{mg} \mathrm{Sb} / 1$ was proposed as a biologically safe concentration which can be used for establishing tentative water quality criteria for $M$. nipponense of this size.

The results of the oxygen consumption rates for the control and exposed juvenile $M$. nipponense were presented in Table 2. After $30 \mathrm{~min}$ (acute), there was an increase in the amount of oxygen consumed in the exposed groups; a maximum increase of $27.3 \%$ was observed at the highest exposure concentration $(1.2 \mathrm{mg}$ $\mathrm{Sb} / \mathrm{l})$. Percentage of oxygen consumption decreased over their respective controls from acute exposure $3^{\text {th }} \mathrm{d}$ to $7^{\text {th }}$ $\mathrm{d}$ during the exposure time. No increasing in oxygen consumption, however, was observed in the recovery period (on $14^{\text {th }} \mathrm{d}$ ) compared with the respective same level groups on $7^{\text {th }} \mathrm{d}$. In the present study, juvenile $M$. nipponense showed no recovery at higher exposure level groups (0.8 and $1.2 \mathrm{mg} \mathrm{Sb} / \mathrm{l})$ after 1-week period in Sbfree water. Former study indicated that exposure to sublethal toxicant concentrations increases respiratory activity, resulting in increased ventilation and increased uptake of the toxin [18]. Later, cytological damage should be related to the decrease in oxygen consumption be- cause the gills are most likely the first target of waterborne heavy metals, including thickening of branchial epithelium and deep changes in hemolymph patterns in the gills with a concomitant increase in vacuolization and reduced hemolymph spaces causing perfusion stagnation [19]. For example, an increased number of nephrocytes in gill filaments, a blackened appearance of the gills, necrosis of gill cells resulting in narrowed or obstructed hemolymphatic vessels, the appearance of a space between the cuticle and the epithelial cells which contains black electron-dense material, and even fragmentation of nuclei within gill cells could be observed when $P$. japonicus were exposed to different concentrations of $\mathrm{Cd}$ for 4 days [20]. A review of the responses of aquatic crustaceans in low ambient dissolved oxygen, mentioned that many crustaceans possess an excellent regulatory ability in their oxygen consumption patterns [21]. We proposed that measurements of oxygen consumption could be used to assess the effects of antimony on sublethal exposure levels of juvenile $M$. nipponense.

The controlled group and adult $M$. nipponense treated with $0.2 \mathrm{mg} \mathrm{Sb} / 1$ showed well-developed hepatopancreatic tubules with star-shaped lumen, and with closely arranged basal laminae surrounding each tubule (Figure 1). Alterations in the structural organization of tubules were observed after $1.0 \mathrm{mg} \mathrm{Sb} / 1$ treatment. Degenerative changes in the lumen, detachment of the basal lamina, and impairment of the structural integrity were observed (Figure 2). Severe hepatopancreatic lesions were found in $M$. nipponense exposed to $4.0 \mathrm{mg} \mathrm{Sb} / 1$. Disorderly and disrupted hepatopancreatic tubules and reduced lumen became more prominent (Figure 3). The crustacean heap-

Table 1. Median lethal concentrations $\left(\mathrm{LC}_{50}\right)$ of antimony to M. nipponense.

\begin{tabular}{ccc}
\hline & \multicolumn{2}{c}{$\mathrm{LC}_{50}(\mathrm{mgSb} / \mathrm{L})$} \\
\hline Life stage & $48 \mathrm{~h}$ & $96 \mathrm{~h}$ \\
Juvenile & 2.240 & 1.635 \\
& $(1.649-3.046)$ & $(1.271-2.103)$ \\
\multirow{2}{*}{ Adult } & 10.083 & 6.748 \\
& $(8.736-11.378)$ & $(5.728-7.950)$ \\
\hline
\end{tabular}

Table 2. Effect of sublethal exposure to antimony on oxygen consumption (mg $\left.\mathrm{O}_{2} / \mathrm{kg}^{\prime} \mathrm{h}\right)$ of juvenile $M$. nipponense.

\begin{tabular}{cccccc}
\hline & Control & $0.1 \mathrm{mgSb} / \mathrm{L}$ & $0.4 \mathrm{mgSb} / \mathrm{L}$ & $0.8 \mathrm{mgSb} / \mathrm{L}$ & $1.2 \mathrm{mgSb} / \mathrm{L}$ \\
\hline acute & $0.653 \pm 0.043^{\mathrm{a}}$ & $0.660 \pm 0.027^{\mathrm{a}}$ & $0.674 \pm 0.042^{\mathrm{a}}$ & $0.808 \pm 0.071^{\mathrm{b}}$ & $0.831 \pm 0.064^{\mathrm{b}}$ \\
day 3 & $0.641 \pm 0.089^{\mathrm{a}}$ & $0.651 \pm 0.063^{\mathrm{a}}$ & $0.647 \pm 0.045^{\mathrm{a}}$ & $0.507 \pm 0.065^{\mathrm{b}}$ & $0.421 \pm 0.033^{\mathrm{c}}$ \\
day 7 & $0.658 \pm 0.043^{\mathrm{a}}$ & $0.644 \pm 0.059^{\mathrm{a}}$ & $0.628 \pm 0.071^{\mathrm{a}}$ & $0.545 \pm 0.077^{\mathrm{b}}$ & $0.504 \pm 0.021^{\mathrm{b}}$ \\
day 14 & $0.659 \pm 0.041^{\mathrm{a}}$ & $0.652 \pm 0.050^{\mathrm{a}}$ & $0.641 \pm 0.058^{\mathrm{a}}$ & $0.573 \pm 0.046^{\mathrm{b}}$ & $0.539 \pm 0.063^{\mathrm{b}}$ \\
\hline
\end{tabular}

All values are given as the mean $\pm \mathrm{SD} ; \mathrm{n}=3$.

Values in the same row with different superscripts differ significantly at $\mathrm{p}<0.05$. 


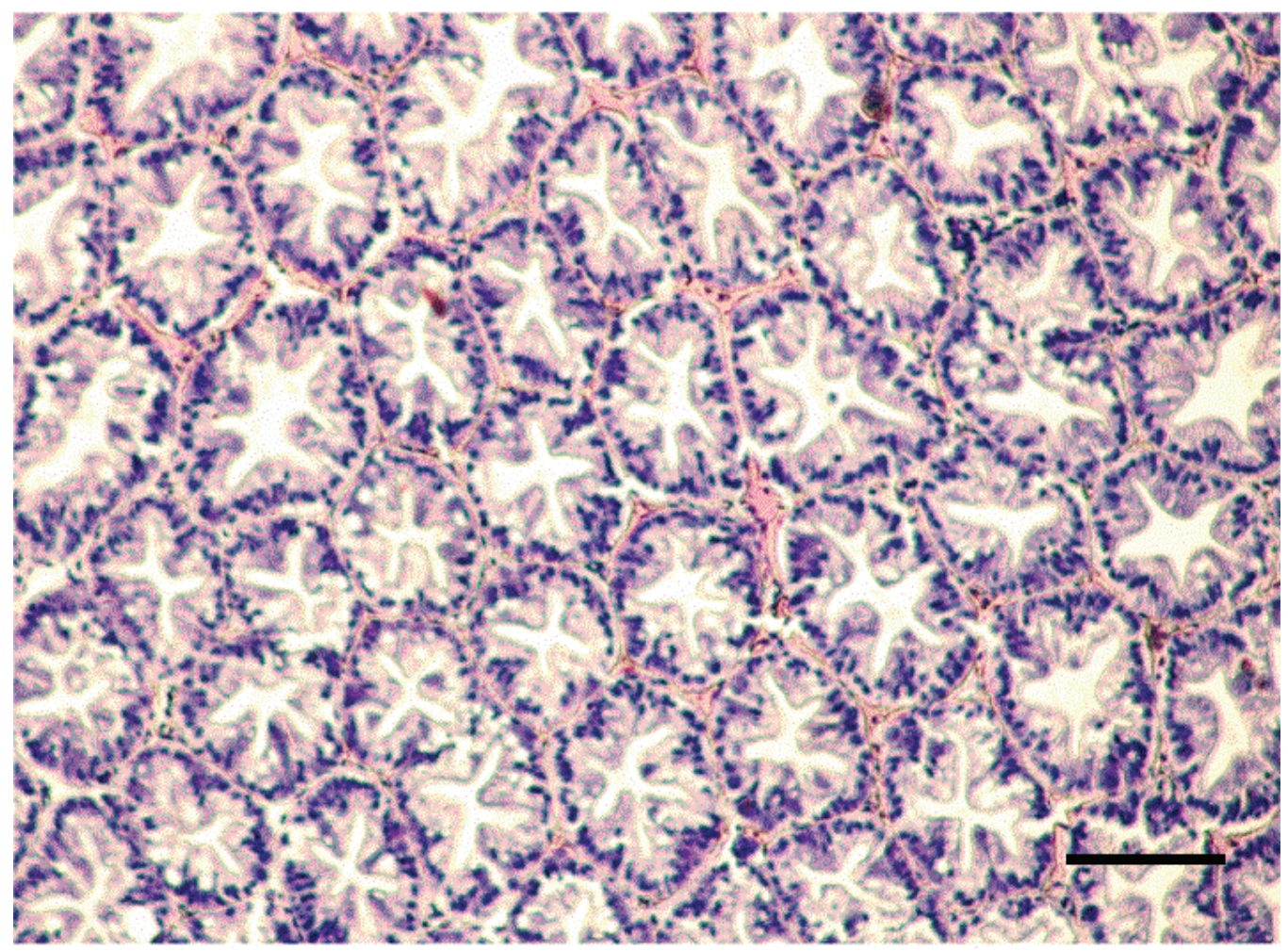

Figure 1. Hepatopancreatic tissue of the adult M. nipponense in the control group. $(\mathrm{bar}=0.1 \mathrm{~mm})$.

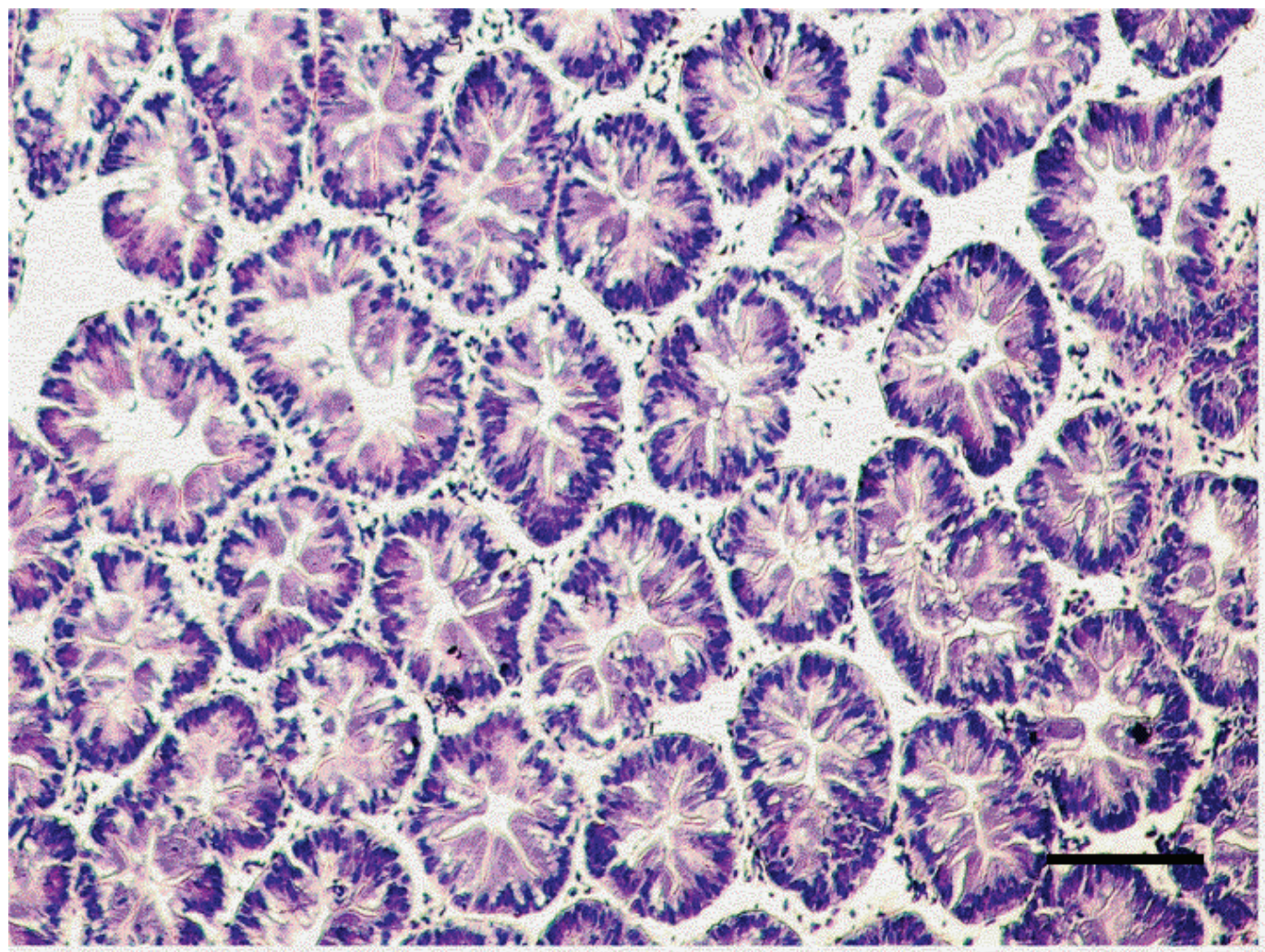

Figure 2. Hepatopancreatic tissue of the adult $M$. nipponense exposed to $1.0 \mathrm{mgSb} / \mathrm{L}$ for $14 \mathrm{~d}$. Note the degeneration of the lumen; impairment of structural integrity can also be seen. $(\mathrm{bar}=0.1 \mathrm{~mm})$. 


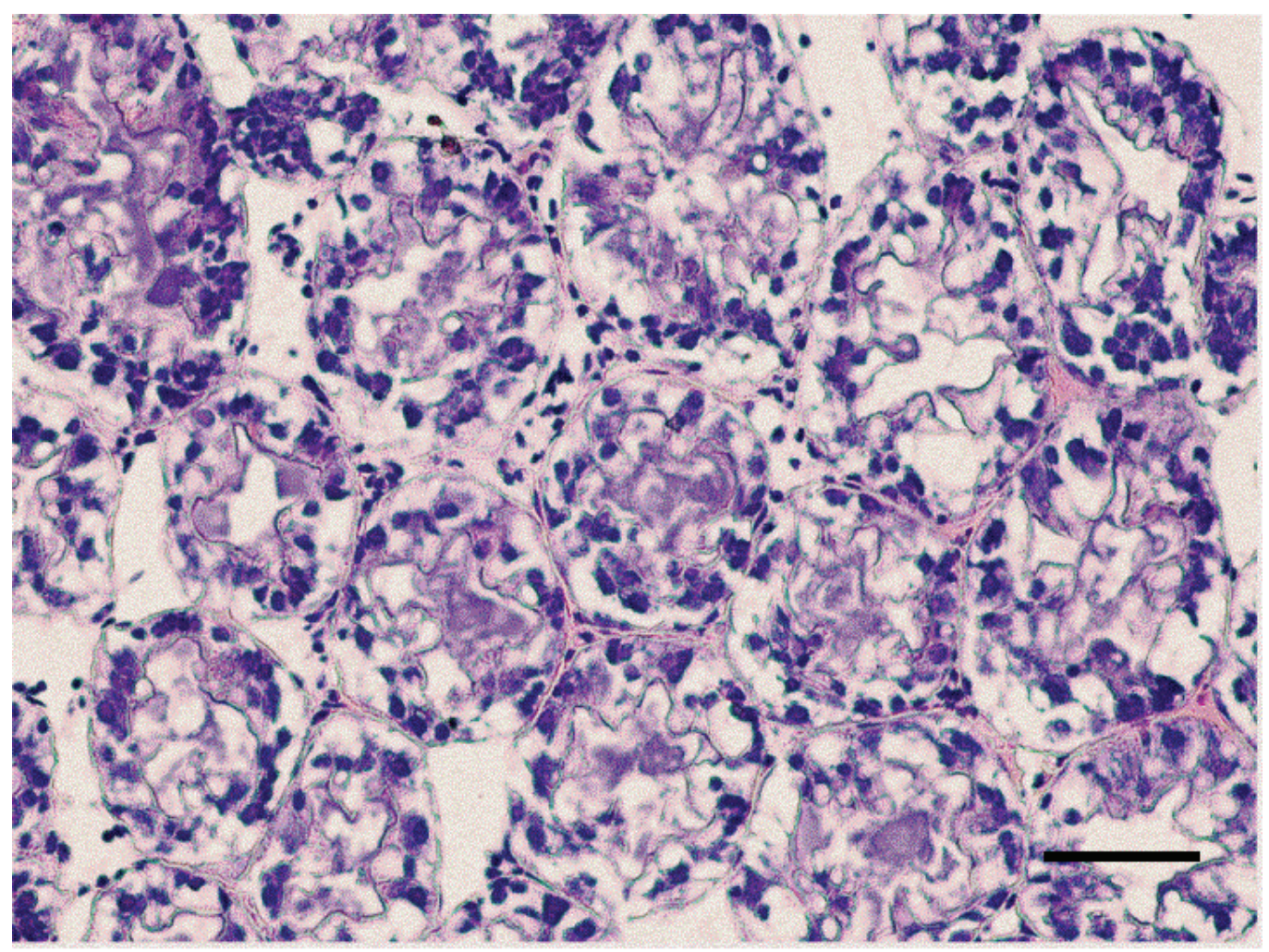

Figure 3. Hepatopancreatic tissue of adult $M$. nipponense exposed to $4.0 \mathrm{mgSb} / \mathrm{L}$ for $14 \mathrm{~d}$. Note the severe damage to the tubules, pronounced hypertrophy of the epithelia cells were also observed. $(\mathrm{bar}=0.07 \mathrm{~mm})$.

topancreas is assumed to be functionally equivalent to the mammalian liver and pancreas and is responsible for major metabolic events, including enzyme secretion, absorption and storage of nutrients, molting, and vitellogenesis [22, 23]. The hepatopancreas is essentially composed of branched tubules and different types of epithelial cells (E-, R-, F-, and B-cells) lining the tubules. It is likely that exposure to a harmful chemical, such as copper sulfate, would be reflected in alterations in the structures of tubules and epithelial cells [24]. Histological alterations have been characterized in freshwater shrimp, such as M. malcolmsonii and various species of Macrobrachium. They are exposed to various chemicals, such as copper, chromium, cadmium, and zinc [25]. Several such structural alterations were noted in the hepatopancreatic tubules of treated $M$. nipponense that had been exposed to antimony in the present study.

\section{Conclusions}

We determined the acute toxicities of antimony to $M$. nipponense in the form of LC50 values. After short-term acute exposure, effects of antimony on oxygen consumption, and hepatopancreatic histopathology of M. nipponense were also demonstrated. Even exposure of $M$. nipponense to lower levels of antimony can result in such deleterious changes, and our finding suggests that antimony is a potential pollutant in aquatic environments, although limited knowledge on the adverse effects of antimony on aquatic animals has been reported to date.

\section{References}

[1] J. Bustamante, D. Lennart, V. Marie, F. Bruce, and O. Sten, "The semiconductor elements arsenic and indium induce apoptosis in rat thymocytes," Toxicology, Vol. 118, pp. 129-136, 1997.

[2] K. Takayanagi, "Acute toxicity of waterborne Se(IV), $\mathrm{Se}(\mathrm{VI}), \mathrm{Sb}(\mathrm{III})$, and $\mathrm{Sb}(\mathrm{V})$ on red seabream (Pargus major)," Bulletin of Environmental Contamination and Toxicology, Vol. 66, pp. 808-813, 2001.

[3] B. Venugopal and T. D. Luckey, "Metal toxicity in mammals (II)," Plenum Press, 1978.

[4] H. Huang, S. C. Shu, J. H. Shih, C. J. Kuo, and I. D. Chiu, "Antimony trichloride induces DNA damage and apoptosis in mammalian cells," Toxicology, Vol. 129, pp. 113-123, 1998.

[5] S. J. Teh, S. M. Adams, and D. E. Hinton, "Histopathological biomarkers in feral freshwater fish populations exposed to different types of contaminant stress," Aquatic Toxicology, Vol. 37, pp. 51-70, 1997. 
[6] H. W. Ferguson, "Systemic pathology of fish," Iowa State University Press, 1989.

[7] R. Lloyd, "Pollution and freshwater fish," Blackwell Press, 1992.

[8] S. Chinni, R. N. Khan, and P. R. Yallapragada, "Oxygen consumption, ammonia- $\mathrm{N}$ excretion, and metal accumulation in Penaeus indicus postlarvae exposed to lead," Bulletin of Environmental Contamination and Toxicology, Vol. 64, pp. 144-151, 2000.

[9] G. R. Ultsch, M. E. Ott, and N. Heisler, "Standard metabolic rate, critical oxygen tension, and aerobic scope for spontaneous activity for trout (Salmo gairdneri) and carp (Cyprinus carpio) in acidified water," Comparative Biochemistry Physiology A, Vol. 67, pp. 329-335, 1980.

[10] J. P. Wu and H. C. Chen, "Effects of Cd and $\mathrm{Zn}$ on oxygen consumption, ammonium excretion, and osmoregulation of white shrimp (Litopenaeus vannamei)," Chemosphere, Vol. 57, pp. 1591-1598, 2004.

[11] A. L. Jr. Buikema, B. R. Niederlehner, and J. Jr. Cairns, "Ological monitoring. Part IV. Toxicity testing," Water Research, Vol. 16, pp. 239-262, 1982.

[12] D. J. Finney, "Probit analysis," Cambridge University Press, 1971.

[13] P. T. Heitmuller, T. A. Hollister, and P. R. Parrish, "Acute toxicity of 54 industrial chemicals to sheepshead minnows (Cyrinodan variegatus)," Bulletin of Environmental Contamination and Toxicology, Vol. 27, pp. 596-604, 1981.

[14] H. C. Lin and P. P. Hwang, "Acute and chronic effects of antimony chloride $(\mathrm{SbCl} 3)$ on tilapia (Oreochromis mossambicus) larvae," Bulletin of Environmental Contamination and Toxicology, Vol. 61, pp. 129-134, 1998.

[15] L. H. Chen, J. L. Yang, and H. C. Chen, "Effects of antimony chloride (III) on aquatic organism: acute test, serum metabolic enzyme activities, and blood cell deformation," Environmental Science: An India Journal, Vol. 2, pp. 1-7, 2006.

[16] L. H. Chen and J. L. Yang, "Acute toxicity of antimony chloride $\left(\mathrm{SbCl}_{3}\right)$ and its effects on oxygen consumption of common carp (Cyprinus carpio)," Bulletin of Environmental Contamination and Toxicology, Vol. 78, pp. 459-462, 2007.

[17] J. B. Sprague, "Measurement of pollutant toxicity to fish. III. Sublethal effects and safe concentrations," Water Research, Vol. 5, pp. 245-266, 1971.

[18] A. S. Murty, "Toxicity of pesticides to fish," CRC Press, 1986.

[19] S. Chinni, R. N. Khan, and P. R. Yallapragada, "Oxygen consumption, ammonia- $\mathrm{N}$ excretion, and metal accumulation in Penaeus indicus postlarvae exposed to lead," Bulletin of Environmental Contamination and Toxicology, Vol. 64, pp. 144-151, 2000.

[20] A. Soegianto, M. Charmantier-Daures, J. P. Trilles, and G. Charmantier, "Impact of cadmium on the structure of gills and epipodites of the shrimp Penaeus japonicus," Aquatic Living Resource, Vol. 12, pp. 57-70, 1999.

[21] B. R. McMahon, "Respiratory and circulatory compensation to hypoxia in crustaceans," Respiration Physiology, Vol. 128, pp. 349-364, 2001.

[22] R. Gibson and P. L. Barker, "The decapod hepatopancreas," Oceanography Marine Biol, Vol. 17, pp. 285-346, 1979.

[23] M. Chanson and D. C. Spray, "Gating and single channel properties of gapjunction channels in hepatopancreatic cells of Procambarus clarkia," Biological Bulletin, Vol. 183, pp. 341-342, 1992.

[24] H. V. Ghate and L. Mulherkar, "Histological changes in the gills of two freshwater prawn species exposed to copper sulphate," Indian Journal of Experimental Biology, Vol. 17, pp. 838-840, 1979.

[25] K. Vijayaraman, "Physiological responses on the freshwater prawn, Macrobrachium malcolmsonii (Milne Edwards) to the heavy metals, cadmium, copper, chromium and Zinc," Ph. D. dissertation, Bharathidasan University, India, 1993. 